\title{
Forging a New Path for Diabetes Care
}

\author{
An Expert Interview with Donna Ryan \\ Immediate Past President, American Association of Diabetes Educators (AADE)
}

DOI: https://doi.org/10.17925/USE.2019.15.1.10

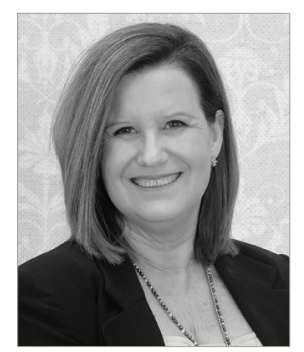

\section{Donna Ryan}

Donna Ryan is Vice President of Population Health for Sacred Heart Health Systems, Ascension Florida. She holds dual licenses as both a registered nurse and registered dietitian and earned her Master's in Public Health from California State University, Northridge. Ryan is also a certified diabetes educator, certified product trainer for insulin pumps and continuous glucose monitors and manages five diabetes programs. Her interests focus on expanding diabetes education and care into new models of care and leveraging technology to improve the quality of diabetes prevention, care, education, and support. She is published and has lectured on inpatient diabetes care, diabetes quality improvement initiatives and building successful business models for diabetes education. Ryan was the 2018 president of the American Association of Diabetes Educators (AADE).

\section{Keywords}

Diabetes education, American Association of Diabetes Educators, diabetes self-management education and support (DSMES), technology

Disclosure: Donna Ryan has no conflicts of interest related to this article.

Review Process: This is an expert interview and, as such, has not undergone the journal's standard peer-review process.

Compliance with Ethics: This article is an opinion piece and does not report on new clinical data, or any studies with human or animal subjects performed by any of the authors.

Authorship: The named author meets the criteria of the International Committee of Medical Journal Editors for authorship for this manuscript, takes responsibility for the integrity of the work as a whole and has given final approval for the version to be published.

Received: March 1, 2019

Accepted: March 12, 2019

Citation: US Endocrinology. 2019;15(1):10-2

Corresponding Author: Donna Ryan, American Association of Diabetes Educators, 2019 Immediate Past President, VP Population Health-Sacred Heart Health System, $5151 \mathrm{~N} 9^{\text {th }}$ Ave, Pensacola,

FL 32503, USA. E: donna.ryan@ascension.org

Support: No funding was received in

the publication of this article.

\section{About The American Association of Diabetes Educators}

The American Association of Diabetes Educators (AADE) is an interdisciplinary professional membership organization dedicated to improving prediabetes, diabetes, and cardiometabolic care through innovative education, management, and support. With more than 14,000 professional members including nurses, dietitians, pharmacists, exercise specialists, and others, AADE has a vast network of practitioners working to improve quality of life through individualized care. AADE operates in a variety of areas to improve care including technology, with solutions like DANAtech.org, type 2 diabetes prevention through the National Diabetes Prevention Program (National DPP), diabetes selfmanagement education and support program accreditation, research, awareness and so much more. Find out everything that AADE has to offer at DiabetesEducator.org.

\section{Q. What are the greatest challenges facing diabetes educators today?}

One of our major challenges as diabetes educators is to improve access and utilization of our services. As experts in diabetes self-management education and support (DSMES), and lifestyle behavior change, we provide evidence-based diabetes education that leads to positive outcomes for those affected by diabetes, prediabetes, or other cardiometabolic conditions, as well as for payors and providers, and cost benefits to healthcare systems. Often, a barrier to our services is lack of referrals or a misunderstanding of the benefits of the diabetes educator consult. We provide so much more than 'education', we drive optimal outcomes through the integration of clinical management, life style behavior change, prevention and support.

A recent AADE clinical study with the Bristol-Myers Squibb Foundation showed just how effective DSMES is, with glycated hemoglobin (HbA1c) reductions as much as $2 \%$ on average. ${ }^{1}$ This builds on existing evidence showing that DSMES can greatly improve outcomes for people with diabetes and increase their overall quality of life. Additionally, people who have received diabetes education are more likely to use primary care and preventive services; better manage their blood glucose, blood pressure, and cholesterol levels; and incur lower health costs. ${ }^{2}$ The outcomes of DSMES are dose dependent, meaning the more interactions with a diabetes educator, the better and more sustained the outcomes. For people living with a chronic condition such as diabetes, education and support is recommended as a life-long intervention and has been shown to be most effective at four critical times: at diagnosis, on an annual basis, when changes in care occur, and when new complicating factors influence self-management. ${ }^{3}$ 
Diabetes education sustains desired outcomes and is less effective when it is utilized as a singular, isolated event, such as only being referred to at the time of diagnosis. Therefore, an essential point that needs to be delivered and hardwired in diabetes care is that effective diabetes education includes ongoing learning and support, delivered over time, with a qualified and trained diabetes educator.

Diabetes self-management training is a benefit covered by Medicare and most health plans when provided by a diabetes educator within an accredited program, typically by referral from the primary care provider Find programs accredited by both AADE and the American Diabetes Association at: DiabetesEducator.org/find.

\section{Q. What were the highlights of your year as president of The American Association of Diabetes Educators?}

So much happened in 2018 it's hard to narrow it down, but here are my highlights from the year:

\section{The Diabetes Advanced Network Access}

The Diabetes Advanced Network Access (DANA) was launched in 2018 as the premier web-based resource and innovative platform for diabetes technologies. As more people with diabetes rely on technology to successfully manage their diabetes, it is necessary for diabetes educators to be technology experts and data interpreters. DANA provides information and resources across a variety of diabetes technology-digital health platforms, continuous glucose monitors, blood glucose monitors, insulin pumps and infusion sets, and insulin and medication delivery devicescontinuing education, training, and trending news. Through generous grants and sponsorships, we are aggressively building an online resource that is already having a real-world impact on the uptake of technology to improve diabetes care and outcomes. Additionally, we were proud to be awarded the 2018 Innovation Award for the $2^{\text {nd }}$ annual .orgCommunity Solutions Day Awards. ${ }^{4}$

\section{Prediabetes initiatives}

We continued work on a multi-year initiative to provide diabetes prevention services through innovative programming, training of lifestyle coaches, and a funding opportunity from the Centre for Disease Control and Prevention $(\mathrm{CDC})$ in order to scale the National DPP to underserved communities.

\section{Population health}

The cornerstone of health equity is population health management, and diabetes population health management in particular. We convened our first population health summit with key constituents and identified areas of strength and opportunities to improve outcomes. An ongoing focus, we are working on practice papers and key guidance to address this important area for the specialty and for healthcare systems.

\section{Vision for the specialty}

The AADE board of directors worked diligently and with many stakeholders including AADE membership, the National Board for Certified Diabetes Educators, people who live with diabetes, provider groups, and other healthcare-focused organizations to identify a future vision for diabetes care and education over the next 10 years. Based on a year-long assessment, focus groups, and thought leader summits, we identified a vision for the specialty of diabetes educators that includes holistic, person-centered care in an integrated model of clinical management and self-management education. Included in this model is the integration of technology, person-centered care, clinical management, behavioral and mental health support, diabetes selfmanagement education, health equity, and access to care. Our vision is that all people on the spectrum of cardiometabolic conditions and diabetes have access to high quality, integrated care that includes a diabetes educator on the care team.

\section{Q. What are your aims for The American Association of Diabetes Educators in 2019?}

Much of 2019 will be focused on laying the groundwork to achieve our new vision for the specialty. This will include providing structure and educational opportunities that allow diabetes educators to be able to take on new skills and expand their roles; revising practice levels, competencies and credentialing needs; building supporting research; meeting with key stakeholders (providers, payers, patient groups) to gain their support and ensure that we stay on track; and considering a possible retitling of the specialty.

This year we are also placing a special focus on diversity and improving access and health equity for people with diabetes. The 2019 AADE Annual Conference (AADE19) has a new "Inclusive Diabetes Care" track that will focus on truly individualized care, with sessions showcasing care for LGBTQ populations, those with hearing impairments, a variety of cultural backgrounds and socio-economic levels, at-risk communities, and so many more.

\section{Q. Could you tell us a little about expanding the National Diabetes Prevention Program to underserved populations?}

In 2017, AADE engaged with the CDC in a funding opportunity to extend the reach of the National DPP into underserved communities. ${ }^{5}$ Our goal has been to scale and sustain the National DPP and to focus on making sure the program is available and serving high-risk populations such as commercial vehicle drivers, the Hispanic community, native communities, and others.

AADE is working directly with National DPP programs in states with high rates of type 2 diabetes to increase diabetes prevention services. These states include Alabama, Arkansas, Arizona, Georgia, Louisiana, Mississippi, New Mexico, and Texas, as well as targeted areas in California to focus on underserved Hispanic populations. Strategic alliances in this process have been key. We are working with several different partners including UnidosUS (formerly known as the National Council of La Raza), Omada Health, the Healthy Trucking Association of America (HTAA), Bridgespan, and the American Medical Association to raise awareness of prevention services and screening, testing, coverage, and enrollment activities.

One initiative focuses on commercial vehicle drivers including truck drivers, who tend to have higher rates of type 2 diabetes. Partnering with the HTAA allows us to reach this population with targeted radio and online programming. Additionally, our work with Unidosus has given us the ability to develop culturally appropriate materials and Spanish-speaking lifestyle coaches for high-risk populations that can then be scaled to other programs. 


\section{Q. What other projects are you involved in at the moment/do you hope to initiate in the future?}

There are so many exciting things happening at AADE and within our specialty right now! We are working closely with our members and stakeholders to connect the dots on diabetes care and create the opportunity for discourse and collaboration that focuses on the whole health of people with diabetes, prediabetes and other cardiometabolic conditions. That means working directly with our state and local chapters, as well as communities of interest, to build content and provide education that is relevant and forward thinking.

Peer support has continued to be a major focus of the Association, as we build on existing relationships with these important communities. This year AADE became a founding sponsor for Beyond Type 2, a peer support site dedicated to supporting those affected by type 2 diabetes. We look forward to better serving those with type 2 diabetes seeking online peer support through this partnership and others.
We are involved in a variety of advocacy issues in partnership with such amazing organizations as the Diabetes Advocacy Alliance. Through our combined efforts, we hope to improve access to diabetes care, eliminate forced medical switching, encourage patient and provider choice, address hypoglycemia in the US, and ensure affordable diabetes medications are available to all.

This year, we are also looking forward to new partnerships and initiatives that push what diabetes education means and how it impacts those we serve. Topics include pediatrics, cultural competence and health literacy, an updated AADE7 Self-Care Behaviors ${ }^{\circledR}$, and new and updated guidelines on a variety of issues facing diabetes educators like individualization of DSMES, inclusive care and population health. Each of these also tie into the future vision for our specialty, creating a cohesive and forward-thinking agenda for 2019. •

1. Bluml B, Kolb L, Lipman R. Evaluating the impact of year-long, augmented diabetes self-management support. Popul Health Manag. 2019;Epub ahead of print. doi: 10.1089/pop.2018.0175.

2. Duncan I, Ahmed T, Li QE, et al. Assessing the value of the diabetes educator. Diabetes Educ. 2011;37:638-57.

3. Powers MA, Bardsley J, Cypress M, et al. Diabetes self-management education and support in type 2 diabetes: a joint position statement of the American Diabetes Association, the American Association of Diabetes Educators, and the Academy of Nutrition and Dietetics. The Diabetes Educator. 2017:43:40-53

4. Org Community. 2018 Solutions Day Award Winners. 2018. Available at: https://orgcommunity.com/about/2018-solutions-day-award-winners/ (accessed March 14, 2019).

5. American Association of Diabetes Educators. Expanding the National Diabetes Prevention Program. Available at: www.diabeteseducator.org/prevention/expanding-the-national-dpp (accessed March 14, 2019). 